\title{
SURGICAL AUDIT - LAPAROSCOPIC CHOLECYSTECTOMY IN A FREE CAMP AT PRIVATE SECTOR HOSPITAL
}

\author{
Abdul Ghani Soomro ${ }^{a}$, Tufail Ahmed Balocha, Moin-ul-Islam ${ }^{b}$ Mairaj Muhammad ${ }^{c}$, Syed Asad Ali \\ ${ }^{a}$ Professor of Surgery Bilawal Medical College LUMHS, Jamshoro. \\ ${ }^{\mathrm{b}}$ District Surgeon, Taluka Hospital, Tando Adam. \\ ${ }^{\mathrm{c} A s s i s t a n t}$ Professor Surgery, Muhammad Medical College, Mirpur Khas .
}

\begin{abstract}
:
BACKGROUND \& OBJECTIVE: Laparoscopic Cholecystectomy is usual method for the treatment of gall bladder stone disease and is practiced all over the world due to many benefits like fasten the recovery time. Furthermore, it reduced the post-operative pain and period of hospital stay. To conduct Surgical Audit and evaluate safety of Laparoscopic cholecystectomy.

METHODOLGY: This prospective study was conducted in a private hospital at Hyderabad during free camps of Laparoscopic Cholecystectomy. Four camps were arranged in 2016 - 2019.

Total number of 190 patients underwent Laparoscopic Cholecystectomy during the study period. The patient's age falls between 12-65 years. A detailed history, relevant investigation and Cardiac fitness were evaluated. All patients underwent four ports Lap-Chole. Data was collected assessed and audit was performed and safety was evaluated.

RESULTS: Total 190 patients operated females $88.45 \%$ and males $11.55 \% .115(60.50 \%)$ were in the range of $30-35$ years followed by $55(28.95 \%)$ patients in the range of $40-50$ years.

$8(4.20 \%)$ patients were converted to open cholecystectomy, 4 due to bleeding from liver bed, 3 patients due to difficult dissection in calots triangle and 1 due to Empyema of gall bladder.

10 patients $(5.50 \%)$ had Trocar site bleeding, 10 patients $(5.50 \%)$ had gall bladder injury, in 4 cases had spillage of stones and 72 patients (38.50\%) developed umbilical port site infection 1 patient develop port site hernia. No mortality was recorded in this study.

CONCLUSION: Our Surgical Audit proves that Laparoscopic Cholecystectomy is a safe procedure on the basis of only $4.2 \%$ intra operative and $5.5 \%$ postoperative complications and gaining wide spread popularity among our population due to less pain, less hospital stay. We recommend other private hospitals to extent such services to our poor population with symptomatic cholelithiasis.
\end{abstract}

KEYWORDS: lap- chole, Surgical Audit, Safety.

How to cite this:

doi: https://doi.org/10.37723/jumdc.v11i2.405

Soomro AG, Baloch TA, Islam M, Ali SA. SURGICAL AUDIT - LAPAROSCOPIC CHOLECYSTECTOMY IN A FREE CAMP AT PRIVATE SECTOR HOSPITAL. jumdc. 2020;11(2):16-20.

doi: https://doi.org/10.37723/jumdc.v11i2.405

This is an Open Access article distributed under the terms of the Creative Commons Attribution License (http://creativecommons.org/licenses/by/4.0), which permits unrestricted use, distribution, and reproduction in any medium, provided the original work is properly cited. 


\section{INTRODUCTION:}

Laparoscopic Cholecystectomy is a gold standard treatment option accepted globally for the gall bladder stone disease. Many trials have demonstrated the advantages of the laparoscopic procedure including decreased post-operative pain, recovery time, duration of hospital stay and early return to work ${ }^{[1]}$.

Cholelithiasis is a common surgical condition causing significant morbidity to patients, and financial burdens on patient's economy ${ }^{[2]}$.

It is estimated that in United States of America about one million patients have Cholelithiasis and is the most common cause of admission to the hospital. Its annual cost is around five billion US dollars ${ }^{[2]}$. Previously the more popular treatment for symptomatic gall stones was open operation through sub costal incision to remove the gall bladder till late 80 s. Open cholecystectomy needs a longer hospital stay and period of recovery ${ }^{[3]}$. Presently more than $83.3 \%$ of cholecystectomy is done laparoscopically ${ }^{[4]}$. In Pakistan also patients are benefited from this minimal invasive surgery (MIS), which has been documented in many studies over the last 15 years ${ }^{[5,6]}$.

In order to curtail financial burden of our poor population free camps were arranged annually to provide relief to needy patients. All the expenses are funded by the local donations.

\section{METHODOLOGY:}

This prospective observational study and audit was conducted in a private sector hospital at Hyderabad city. The study has been approved by the ethical review committee of Hajiani Day \& Night Hospital Hyderabad. Patients were registered from different parts of Hyderabad city and nearby small towns like Matiari, Sangher, Thatta and Tharparker districts of Sindh. Publicity of the camps was made by newspapers and displaying banners in city and suburbs. Four camps were arranged on annual basis in the year 2016, 2017, 2018 and 2019. Patients were registered and relevant investigations like blood complete picture, blood sugar, liver function test, urine detailed report, $\mathrm{HbsAg}$, Anti HCV, coagulation profile and ultrasound abdomen were carried out. The patients with confirmation of cholelithiasis were

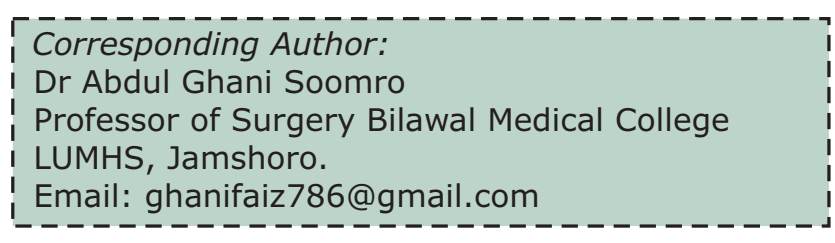

then enrolled with well-prepared file which included all necessary information along with cell phone number. Patients were called on the day of surgery and were admitted after anesthesia fitness. Two to three patients were operated on daily basis. All the enrolled patients were operated within the period of 20-25 days. All the arrangements were beard through donations which included discharge medicines. All the patients were operated under general anesthesia; laparoscopic cholecystectomy was done with four port technique. Data was collected which included patient demographics, operative findings, conversion rate, operative \& post-operative complications, length of hospital stay and mortality.

\section{RESULT:}

One hundred ninety patients were registered and underwent laparoscopic cholecystectomy. Age ranged from 12-65 years. Males were 22 $(11.55 \%)$ and females were $168(88.45 \%)$. Regarding age distribution 115 (60.50\%) patients were between $30-35$ years, 55 (28.95\%) patients were between $40-50$ years, $19(10.00 \%)$ patients were between 55-60 years and 01 patient was of 12 years (See Table-I).

Out of 190 patients $08(04.20 \%)$ cases were converted to open cholecystectomy, 04 due to bleeding from liver bed, 03 patients due to difficult dissection in calot's triangle and 01 due to Empyema of gall bladder (see Table-II).

Intra operatively 08 patients $(04.40 \%)$ had Trocar bleeding, 10 patients $(05.50 \%)$ had gall bladder injury, and 10 patients $(2.20 \%)$ had a spilled stone. Post operatively 72 (39.56\%) patients had umbilical port infection and only 01 patient reported after six months with port site hernia. There was no recorded mortality in this study (Table-III).

178 patients ( $93.68 \%$ ) have chronic cholecystitis and 12 patients $(06.32 \%)$ have acute cholecystitis. For histopathology see (Table-IV). 
In $95 \%$ of the cases operative findings were correlated with ultrasonic report. In $5 \%$ of cases operative findings did not matched with the ultrasound report on the basis of gall bladder wall thickness, number of stones single/ multiple and any other associated problem not reported by ultrasonologist. None of the patients had stone in common bile duct.

Table-I: Patients demographics $(n=190)$.

\begin{tabular}{|c|c|c|}
\hline Gender & Patients No & Patient \% \\
\hline Male & 22 & 11.55 \\
\hline Female & 168 & 88.45 \\
\hline Age & \multicolumn{2}{|c|}{} \\
\hline 12 years & 01 & 0.55 \\
\hline $30-35$ years & 115 & 60.50 \\
\hline $40-50$ years & 55 & 28.95 \\
\hline $55-60$ years & 19 & 10.00 \\
\hline
\end{tabular}

Table-II: Outcome of patients $(n=190)$.

\begin{tabular}{|c|c|c|}
\hline Out come & Patients No & \% \\
\hline Laparoscopic cholecystectomy & 182 & 95.80 \\
\hline Converted Open cholecystectomy & 08 & 04.20 \\
\hline Cause of Conversion & \multicolumn{2}{|l|}{} \\
\hline Bleeding & 04 & 50.00 \\
\hline Difficult Dissection & 03 & 37.50 \\
\hline Empyema & 01 & 12.50 \\
\hline
\end{tabular}

Table-III: Intra/ post-operative complications $(n=182)$.

\begin{tabular}{|c|c|c|}
\hline Complication & No. of Cases & \% \\
\hline Trocar Site Bleeding & 08 & 04.40 \\
\hline Gall Bladder injury & 10 & 05.50 \\
\hline Spilled Gall Stones & 10 & 05.50 \\
\hline Umbilical Port site infection & 72 & 39.56 \\
\hline Port site Hernia & 01 & 0.55 \\
\hline
\end{tabular}

Table-IV: Histopathology $(n=190)$.

\begin{tabular}{|c|c|c|}
\hline Diagnosis & No. of Cases & \% \\
\hline Chronic Cholecystitis & 178 & 93.68 \\
\hline Acute Cholecystitis & 12 & 06.32 \\
\hline
\end{tabular}

\section{DISCUSSION:}

Laparoscopic Cholecystectomy is a gold standard treatment accepted in the developed world for symptomatic cholelithiasis. In our country still open cholecystectomy is in practice in some remote areas due to non-availability of facility and high cost.

Hence Laparoscopic Cholecystectomy is a financial burden and cost effective for our poor community as compared with the conventional open cholecystectomy. However, it must be realized that the overall cost is reduced due to short hospitalization, less analgesic requirements and early return to work ${ }^{[7,8,9]}$. Lombardo et al also reports an overall reduced cost on the basis of above observations ${ }^{[10]}$. In our audit, a privilege is given to our poor 
population and all the expenses are funded by the donations.

In our study the number of female patients $(88 \%)$ were high due to the disease being more prevalent in females also reported in other studies ${ }^{[10,11,12,13]}$.

Obvious benefits of laparoscopic cholecystectomy like less pain and need for post-operative analgesia, short post-operative hospital stay, early discharge to home and early return to work was also observed in our study. In our study $93 \%$ of the patients were discharged within 24 hour and only $7 \%$ patients within 48hourspost operatively compared to reports by other studies ${ }^{[13,14]}$.

In our study conversion to open cholecystectomy was in 8 patients $(4.40 \%)$ due to bleeding from liver bed, difficult dissection and empyema gall bladder, similar findings were reported by another local study by Malik A. ${ }^{[15]}$. However $14 \%$ conversion rate is reported by Michael et al recently using a scoring system ${ }^{[16]}$. In our study the reported port site infection is very high $(38.50 \%)$ at the $1 \mathrm{~cm}$ umbilical port probably due to large size and retrieval of gall bladder specimen without pouch. However allow incidence of only $3.23 \%, 2 \%$ and $8 \%$ respectively are reported in other studies ${ }^{[17,18]}$. In our study we observed laparoscopic cholecystectomy is a safe procedure with less intra and postoperative complications and is well tolerated by the patients. Ven de groot et al has also reported similar observations in a recent study ${ }^{[18]}$. Vishal gupta et al also reported safe laparoscopic cholecystectomy is his study ${ }^{[19]}$. In another study Ven de graat et al also observed safety of LC regarding less CBD injuries ${ }^{[20]}$.

\section{CONCLUSION:}

Our Surgical Audit proves that Laparoscopic Cholecystectomy is a safe procedure on the basis of only $4.2 \%$ intra operative complications and $5.5 \%$ post-operative complications and gaining wide spread popularity among our population due to less pain, less hospital stays and early return to the work. We recommend other private sector hospitals to extent such services to our poor population with symptomatic cholelithiasis.

\section{REFERENCES:}

1. Feng JW, Yang $X \mathrm{H}$, Liu CW, Wu BQ, Sun DL, Chen XM, et al. Comparison of laparoscopic and open approach in treating gallbladder cancer. Journal of Surgical Research. 2019;234:269-276 PubMed PMID: 30527484.

2. Kapoor T, Wrenn SM, Callas PW, Abu-Jaish W. Cost analysis and supply utilization of laparoscopic cholecystectomy. Minimally invasive surgery. 2018; 7838103. Doi: $10.1155 / 2018 / 7838103$

3. Sinha S, Hofman D, Stoker DL, Friend PJ, Poloniecki JD, Thompson MM, et al. Epidemiological study of provision of cholecystectomy inEngland from 2000 to 2009: retrospective analysis of Hospital Episode Statistics. Surgical endoscopy. 2013;27(1):162-175. Doi: 10.1007/ s00464012-2415-0

4. Tanović $H$, Mesihović R. Differences in the postoperative course and treatment in patients after laparoscopic and standard cholecystectomy. Medicinski arhiv. 2003;57(4):219-222.

5. Wakabayashi G, Iwashita Y, Hibi T, Takada T, Strasberg SM, Asbun HJ, et al. Tokyo Guidelines 2018: surgical management of acute cholecystitis: safe steps in laparoscopic cholecystectomy for acute cholecystitis (with videos). Journal of Hepato biliary pancreatic Sciences. 2018;25(1):73-86.

6. Cawich SO, Albert M, Singh Y, Dan D, Mohanty S, Walrond $M$, et al. Clinical outcomes of single incision laparoscopic cholecystectomy in the anglophone Caribbean: a multi centre audit of regional hospitals. International journal of biomedical science: IJBS. 2014;10(3):191195. PMID: 25324700

7. Vera K, Pei KY, Schuster KM, Davis KA. Validation of a new American Association for the Surgery of Trauma (AAST) anatomic severity grading system for acute cholecystitis. Journal of Trauma and Acute Care Surgery. 2018;84(4):650-654.

8. Ward E, Fox K, Ricketts L, McCaw-Binns AM, Gordon G, Whorms S. A review of hospital care in Jamaica: morbidity and mortality patterns, resource allocation and cost of 
care. West Indian Medical Journal. $2001 ; 50($ S2):21. Doi: $10.1016 / j . j s s$. 2018.03.036

9. Lombardo S, Rosenberg JS, Kim J, Erdene S, Sergelen O, Nellermoe J, Finlayson SR, Price RR. ScienceDirect Cost and outcomes of open versus laparoscopic cholecystectomy in Mongolia. Journal of Surgical Research. 2018;229:186-191.

10. Mohammad SH, Hinduja T, Fatima S. Complications of Iaparoscopic cholecystectomy in acute cholecystitis. Journal of Surgery Pakistan (International). 2008;13(2):59-61.

11. Tan JT, Suyapto DR, Neo EL, Leong PS. Prospective audit of laparoscopic cholecystectomy experience at a secondary referral centre in South Australia. ANZ journal of surgery. 2006;76(5):335-338. Doi: 10.1111/j.1445-2197.2006.03721.x

12. Chan AC, Chung SC, Lau JW, Brockwell J, Li MK, Tate JJ, et al. Laparoscopic cholecystectomy: results of first 300 cases in Hong Kong. Journal of the Royal College of Surgeons of Edinburgh. 1994;39(1):2630. PMID: 7515426

13. Gul T, Kamran W, Andaleeb U, Sahar S, Muqim R, Salman M. An audit of Laparoscopic Cholecystectomy in a tertiary care hospital. Pakistan Journal of Surgery. 2013;29(4):236-241.

14. Malik AM. Difficult laparoscopic cholecystectomies. Is conversion a sensible option. Journal of Pakistan Medical Association. 2015;65(7):698-700.

15. Sugrue $M$, Coccolini F, Bucholc $M$, Johnston A. Intra-operative gallbladder scoring predicts conversion of laparoscopic to open cholecystectomy: a WSES prospective collaborative study. World Journal of Emergency Surgery. 2019;14(1):12.

16. Shah AA, Bhatti UF, Petrosyan M, Washington G, Nizam W, Williams M, et al. The heavy price of conversion from laparoscopic to open procedures for emergent cholecystectomies. The American Journal of Surgery. 2019;217(4):732-738. Doi: 10.1016/j. amjsurg.2018.12.038
17. Al Ghnaniem R, Benjamin IS, Patel AG. Meta analysis suggests antibiotic prophylaxis is not warranted in low risk patients undergoing laparoscopic cholecystectomy. British journal of surgery. 2003;90(3):365-6. Doi:10.1002/bjs.4033

18. Van de Graaf FW, van den Bos J, Stassen LP, Lange JF. Lacunar implementation of the critical view of safety technique for laparoscopic cholecystectomy: results of a nationwide survey. Surgery. 2018;164(1):31-39. Doi: 10.1016/j.surg. 2018.01.016

19. Gupta V, Jain G. Safe laparoscopic cholecystectomy: Adoption of universal culture of safety in cholecystectomy. World journal of gastrointestinal surgery. 2019;11(2):62-84. Doi: 10.4240/wjgs. v11.i2.62 PMID: 30842813

20. Van de Graaf FW, Zaïmi I, Stassen LP, Lange JF. Safe laparoscopic cholecystectomy: a systematic review of bile duct injury prevention. International Journal of Surgery. 2018;60:164-72. Doi: 10.1016/ j.ijsu.2018.11.006

\section{Authors' Contribution:}

Abdul Ghani Soomro: Substantial contributions to the conception or design of the work or the acquisition, analysis, or interpretation of data for the work.

Tufail Ahmed Baloch: Final approval of the version to be published.

Moin-ul-Islam: Final approval of the version to be published.

Syed Asad Ali: Help in data collection analysis and final draft of study. Drafting the work or revising it critically for important intellectual content.

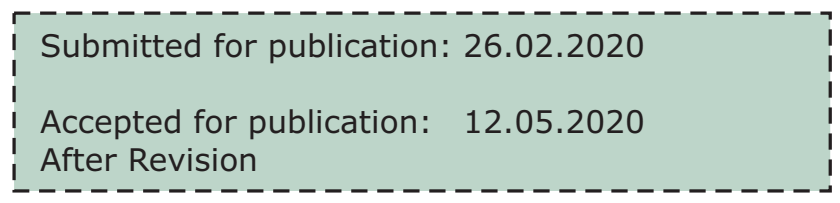

